perpendicular to the optical axis, otherwise images which should be round will appear elliptical and wrong impressions will consequently be produced. The test for spherical aberration also has to do with the form of the image. An instrument is defective in this respect if the light, instead of being concentrated into a well-formed image, appears scattered in the field of view. The image of a bright star out of focus should show well defined concentric circles of light. Chromatic aberration, as its derivation indicates, refers to color effects about an image. If the moon is examined through the telescope certain colors will be visible around the edge of the disk; usually blue and orange predominate. These are caused by the unequal refraction of different light rays. This defect, which was very marked in the early telescopes, is for the most part eliminated by the achromatic lens, but not entirely. Even the best lenses produce objectionable colors in some degree but the effect should be at a minimum if the telescope is to be called satisfactory.

All the above tests applied to our little one and one-half inch lens yielded very fair results. The test for spherical aberration was especially favorable, for the image of Arcturus out of focus suggested at once a cross-section of a regular shaped tree trunk where the rings denoting its age show conspicuously

In order to determine the magnifying power of our telescope, a very simple but entirely satisfactory method is the following: having "set" for infinite focus in advance, that is, having determined at night the position of the draw tube which produces the best stellar image. we direct the telescope toward the sky in the daytime. Then holding the head at some distance from the eyepiece a small bright circle is seen surrounded by a dark ring. This bright circle, an image of the object glass seen in the eyepiece, is called the emergent pencil of ligh and its diameter can be easily measured by means of a small instrument called a dynamometer, or a home-made scale such as is described in Byrd's Laboratory Manual, section 20 . The magnifying power is found by dividing the diameter of the object glass by the diameter obtained by measurement. Using the latter device I found that the mean of five series of measurements made on five different days gave .068 inches. Combining this with the mean of seven measurements with the dynamometer, my adopted value for the diameter of the emergent pencil of light is .065 , which gives for the magnifying power of my telescope 23 diameters.

Another preliminary observation, which is closely related to the preceding, is to determine more exactly the diameter of the field of view in time units which are easily reducible to minutes and seconds of arc. A knowledge of this value is often very helpful in later observations and may be ascertained as follows: A star (preferably near the meridian in the south), is watched as it crosses the field of view and an assistant with a watch crosses the field of view and an assistant with a watch
notes the instants when the observer calls "time" as the star enters and leaves the field, that is at the beginning and end of the transit. If the star chosen is not on or near the equator, the resulting interval must be reduced to the equator by multiplying the observed time by the cosine of the star's declination. These methods of testing the telescope are typical and not exhaustive. They show what may be done by the person who intends to make the most intelligent use of his instrument.

Many of the observations possible for the common two and one-half-inch portable telescopes are also well adapted to this less pretentious type of instrument which, though lacking the advantages of a larger objective and more stable mounting, compensates for these deficiencies by offering a simple, effective substitute, deficiencies by offering a simple, effective substitute,
easily and quickly handled and therefore more available for use by those who observe for recreation than a larger more elaborately designed model.

The one and one-half inch telescope described represents not more than $\$ 4$ in actual cost and a few hours pleasurably and profitably spent. Such an instrument will not only meet the needs of many amateur observers will not only meet the needs of many amateur observers
but will prove especially helpful to all who are beginning the study of Astronomy.

REFERENCEs: Byrd's "Laboratory Manual"-Appendix
Fowler's "Popular Telescopic Astronomy"; Proctor's "Hal Fowler's "Popular Telescopic Astronomy"; Proctor's "Hal"
hours With a Telescope"; McKready's "Beginners Star Book."

\section{A Kashmir Barrage of Hail} By William Beebe

IN battle we use such similes as, a storm of bullets, a rain of shells, but the strength of this comparison lies usually in the thoughtless acceptance of the figure of speech, rather than in any actual similarity. Cnce or
twice in my life I have experienced natural storms which, in intensity and power of destruction, equalled any temporary hell which man, with the aid of gas or high explosive, has been able to achieve.

A month ago in Trafalgar Square, London, where there was literally a hail of shrapnel from the British antiaircraft guns, there came to mind the most terrible hail- storm I have ever experienced, on the borderland betwee

I was camped in a wonderful hanging valley with th last outpost dak bungalow snuggled in the center, surrounded by a host of tall spired silver firs and deodars. Spring was at its height, and the open spaces were almost paved with a mass of white strawberry blossoms, with roses and pink-flowered raspberries in the underbrush. In the dense shade of the deodars were lilies-of the-valley and great banks of maiden's hair tern. Birds were courting or building, or, as in the case of an impeyan pheasant
sitting on eggs.

One day I surprised a troop of great gray langur monkeys in the act of robbing this nest, which fortunately I had already photographed. As I came along the slope the marauders swung past me, old and young hurlin themselves recklessly from spire to spire. Tree after tree shook and bent as in a terrific gale of wind; smal dry branches crashed and splintered; cones, needles, and twigs rained to the ground as the troop rushed by. The uproar which these banderlogs create has usually but lictle effect upon the lesser creatures of the forest. They well know the danger as well as the limitations of the four-handed folk.

But when this troop passed, quiet did not settle down. There was no wind, no movement of the needles. Eve the ferns hung motionless. But there was sinister undercurrent more potent than noise of elements. Something was about to happen, and not concerning any on animal, or in any one glade. The birds were restless and their notes were those of anxiety. Pheasants called in a way which they should not have done except in earl morning; small creatures rustled here and there amon the leaves. I picked up my gun and walked toward amp.

I crossed two bridges. Still no wind, but a sound of restless life everywhere, a tense uneasiness. And then came the climax, swiftly, mercilessly. From the Tibetan snow-peaks in the distance billowed a breath of cold air-icy, unfriendly - and a dark cloud swept across th sun. The mist grew thicker and closed down. Th birds and forest creatures became silent as death, and for as long as two minutes the silence was oppressive. Then in the distance, dimly through the fog, the trees bent and straightened, the mist yellowed and a drop of rain fell. Finally, came a sound as strange as any in the world, the noise of ice falling on flowers and leaves a mitrailleuse volley of hail such as only the great Himalayạs know.

Lashed by the ice, our horses whinnied with pain and fright, and although wild mountain ponies, crowded close to us beneath the shelter of the dak. They pushed in out of the downpour, and while they had been exposed only to the first, rather light, fall, yet their coats were covered with welts as if from blows of finely divided thongs of a whip.

After fifteen minutes of hail such as we are familiar with in the States, the stones grew larger and the downpour more furious, until the crash of falling ice dominated all other sounds. The floor of the valley became whit and the hail-stones-now much larger than marblesbounced and leaped high after their impact with the ground.

Leaves and whole fans of spruce needles were tor away and covered the bruised blossoms of the forest slopes. The air was a screen of straight lines, breaking near the ground into a maze of dancing, splintering crystal balls.

Before the bombardment ended I put out my hand with the result that one stone struck my thumb and lamed it for three days. Without warning, the sun cam out and made of the storm a translucent tapestry, throug which the broken foliage was dimly visible. It was so wonderful, so unlike anything I had ever seen, that I forgot momentarily the terrible damage-the shredded foliage, the host of stricken nestlings and creatures which had not found a safe retreat. When the las missile had fallen I wondered whether the most hardy tenant of the forest had survived. And nature in mockery of my ignorance, having ceased her cruel torren sent out the frailest of frail butterflies, flickering it copper wings before me in the sun.

I found others which had not been so fortunate, and in one spot, beneath a thin-leaved bush were thirty-eight good-sized butterflies, with wings only slightly torn but all killed and partly buried beneath a mass of jellied hail-stones. About fifty per cent of the nests which had under observation were destroyed, but some were preserved by overhanging banks. This was the case with was quite unharmed, sheltered in a niche, in the side of a steep grassy bank.

Not far a way, behind a bit of loosened deodar bark, was a most delicate nest of a rufus-capped titmouse, with three dead and one unharmed young bird. Two big hailtones had crashed down, one being wedged a few inches above the nest, while the other had fallen with full force into the mass of moss and pheasant feathers, and then slipped over the edge. The forlorn youngster, balancing himself on a bit of stick, looked as if life held out no hope of any kind, but at the chirp of his parents, he opened his eves, and when I left him he had his mouth wide agape, begging as only infant birds can.

I found traces of many other tragedies, one of the most unexpected being the bodies of two giant flying squirrels. These splendid rodents, which weigh as much as five pounds and are sometimes over three feet in length, are not uncommonly seen in the dusk of evening, volplaning from trunk to trunk in these mighty evergreen forests. These had apparently been sleeping in a half hollowed out space behind some bark which had been torn away, and the ice had stunned and killed them before they could escape. Lizards were flattened on rocks and logs, and the total destruction of animal life must have been very great. Certainly no creature of the ice. A chicken in an open crate was so injured that we had to kill it.

Taken altogether, this Kashmir storm was the most severe one I have ever witnessed, and my servants would have had a bad time of it if they had not been able to reinforce the sloping walls of their tent and so keep under cover. As it was, great rents were torn in the canvas and the men were pretty badly frightened by the time it was all

\section{The Gibraltar Straits Tunnel}

INTEREST has lately revived in the scheme for a tunnel beneath the Straits of Gibraltar, which has, like that for a railway link between England and France, made an appeal to engineers for a generation or more. Some of the technical aspects of the project have been under discussion before the French Society of Civil Engineers, and it does not appear to be thought that there are any abnormal difficulties on the engineering side. Owing to the depth of water and character of the sea bed and the underlying strata, it would be necessary to construct such a tunnel at a depth, it is believed, of some 840 metres; and the length between Tarifa, the suggested point of departure on the Spanish side of the Straits, and either of the alternative points of emergency on the Morocco coast, would be about $151 / 2$ miles. It is assumed by the advocates of the scheme that the cost of construction would not exceed $£ 10,000,000$, but necessary port improvements would call for the expenditure of an additional $£ 4,000,000$. There can be no doubt that the linking of the European and African railway systems would give a great stimulus to French and Spanish trade, and on the assumption that the tunnel beneath the Straits of Dover is constructed, the tunnel would provide over the Trans-African railway a through route between England and South Atrica. The scheme now put forward by M. Henri Bressler does not differ in its essential aspects from that planned by Berlier twenty years ago; but it is felt that the case for the tunnel has been strengthened in the interval, and it is believed that the capital could now be found without seeking any financial aid from either the French or Spanish Government.-Engineering Supplement of the London Times.

\section{Pearl Shell Industry in Australia}

Tне pearl shell industry is largely carried on in Australia, especially in Queensland and other parts of the country. The pearl oyster is found along the northern and western coasts of Australia for a distance of over 2,000 miles. On the north coast the pearls taken out are of small size, but the shells themselves are an important commercial product. The Shark Bay pearl industry is carried on both for pearls and shells, usually with the aid of diving apparatus. In tropical Queensland, pearl shell diving is actively pursued and is by far the most important of the fishing industries. In connection with it we may also mention that tortoise shell is obtained on these same coasts. Two distinct species of mother of pearl are exported from western Australia, the principal trade being done with the large hell (Meleagrina margaritifera), whose distribution is limited to tropical waters. It is used for the larger manufactured articles such as knife and fork handles, large buttons and inlaid work. The largest and finest pearls are obtained from this shell. The second species is the one known commercially as the Shark Bay variety (Meleagrina imbricata), which is smaller and used chiefly for the manufacture of small buttons. The exports of pearl shell from Australia during the year ending June 1916 were value at nearly $\$ 5,000,000$, which is about 13 per cent increase over the preceding year. 